PERNIK Jurnal PAUD, VOL 1 NO.1 September 2018

\title{
PENINGKATAN KECERDASAN INTERPERSONAL MELALUI BERMAIN MUSIK (Penelitian Tindakan Anak Usia 4-5 Tahun di TK Pertiwi Tanjung Raja Tahun 2017)
}

\author{
Santa Idayana Sinaga \\ Program Studi Pendidikan Guru Pendidikan Anak Usia Dini \\ Universitas PGRI Palembang \\ e-mail:paudsanta@gmail.com
}

\begin{abstract}
The purpose of this research was to describe the implementation process play music and to understand improving interpersonal intelegence of children $4-5$ years old through play music. The study was conducted on group A Kindergarten with of seventen children. This study used action research methods by Kemmis and Taggart which consist of 4 stages (plan, action, observation and reflection). This study consisted of two cycles, each cycles consisting of 8 sessions. Data collecting techniques used observation, field notes and documentation. Data analysis using quantitative and qualitative data. Quantitative data analysis with descriptive statistics that compare the result obtained from the first cycle and the second cycle. Analysis of qualitative data by analizing data from the observation, fields notes and documentation during the study to the steps of data reduction, data display and data verification. The result of this study showed that there was the improving interpersonal intelegence through play music with score in pre cycle 33,8 had improvement to 50,4 and become 60,7 in cycle II and excellent growing category.
\end{abstract}

Keywords : Interpersonal Intelegence, Play Music, Action Research

\begin{abstract}
Abstrak : Tujuan hasil penelitian ini adalah mendeskripsikan proses penerapan bermain musik dan untuk mengetahui peningkatan kecerdasan interpersonal anak usia 4-5 tahun melalui bermain musik. Penelitian ini dilakukan pada anak kelompok A yang berjumlah 17 orang. Penelitian ini adalah penelitian tindakan dengan metode Kemmis dan Taggart yang terdiri dari 4 tahap yaitu (rencana, tindakan, observasi dan refleksi). Penelitian ini terdiri dari 2 siklus masing-masing siklus sebanyak 8 pertemuan. Teknik pengumpulan data menggunakan observasi, catatan lapangan, dan dokumentasi. Analisis data menggunakan kuantitatif dan kualitatif. Analisis data kuantitatif dilakukan dengan deskripsi statistik untuk membandingkan pra siklus sampai siklus II. Tahap-tahap analisis kualitatif adalah reduksi data, display data dan verifikasi. Hasil penelitian menunjukkan terdapat peningkatan kecerdasan interpersonal melalui bermain musik dengan skor pada pra siklus 33,8 meningkat menjadi 50,4 pada siklus I, dan mengalami peningkatan sebesar 60, 7 pada siklus II dengan kategori berkembang sangat baik.
\end{abstract}

Kata Kunci : Kecerdasan Interpersonal, Bermain Musik, Penelitian Tindakan 


\section{PENDAHULUAN}

Dewasa ini di bagian negara manapun khususnya Indonesia masih menganggap bahwa seseorang yang cerdas adalah mereka yang cerdas secara kognitif saja, padahal sebenarnya anak adalah sosok individu unik yang memiliki kecerdasan yang berbeda antara satu dengan yang lain. Kecerdasan berpengaruh besar terhadap kehidupan anak dan masa depannya terutama kecerdasan interpersonal.Kecerdasan interpersonal ini berhubungan dengan kemampuan seseorang untuk berinteraksi dengan orang lain, memiliki sifat peka, memiliki intuisi yang baik dan peduli terhadap lingkungan sosial disekitar anak.

Hasil penelitian Brand dan BarGil (2010:1-17) yang berjudul Improving Interpersonal Communication through Music menyatakan bahwa komunikasi interpersonal anak meningkat melalui musik. Musik berpengaruh terhadap komunikasi anak yang terkait dengan cara bagaimana anak berkomunikasi dengan orang lain. Dalam penelitian ini penulis memilih bermain musik karena sangat besar dampaknya terhadap perkembangan anak.

Selanjutnya Hallam (2010:110) menyatakan bahwa The power of music : its impact on the intellectual, social and personal development of children and young people. Hasil penelitian menunjukkan bahwa dengan mendengarkan musik berpengaruh terhadap intelektual, perkembangan sosial, personal, bahasa dan kreativitas pada anak-anak dan orang muda.

Katrin Hille, et al (2011:1-6) Association Between Music Education, Intelligence, And Spelling Ability In Elementary School. Hasil penelitian menunjukkan bahwa ada hubungan antara pendidikan musik, kecerdasan dan kemampuan mengeja pada anakanak di sekolah dasar yang berusia 8 tahun. 
Selain itu penelitian Bolduc (2009:1-8) Effects Of a Music Programme On Kindergartners Phonological Awareness Skills. Hasil penelitian menunjukkan bahwa program musik berpengaruh terhadap kemampuan kesadaran fonologi di taman kanak-kanak. Filivopic dan Garic (2011:1-19) The Influence of Music on the Children"s Art Expression. Hasil penelitian menunjukkan bahwa musik berpengaruh terhadap ekspresi seni (kreativitas) anak-anak

Selanjutnya penelitian Paquette dan Rieg (2008:1-10) Using Music to Support the Literacy Development of Young English Language Learners. Hasil penelitian menunjukkan bahwa literasi dan kreativitas anak meningkat melalui musik terhadap anak-anak yang belajar bahasa inggris awal

Dari hasil-hasil penelitian relevan di atas dapat kita lihat bahwa musik sangat besar dampaknya terhadap perkembangan anak. Ada yang berdampak pada komunikasi interpersonal anak, aspek perkembangan anak, kesadaran fonologi, literasi dan kreativitas. Dalam penelitian ini penulis ingin mengetahui bagaimana musik dapat meningkatkan kecerdasan interpersonal anak. Penelitian ini sangat penting dilakukan mengingat bahwa kecerdasan interpersonal adalah aspek penting yang menunjang kesuksesan seseorang berkaitan dengan bagaimana seseorang berhubungan dan bersikap dengan orang lain.

Berdasarkan pengamatan saya di TK Pertiwi Tanjung Raja pada kelompok A ( usia 4-5 tahun) dengan jumlah anak 17 orang. 6 anak laki-laki dan 11 anak perempuan hal ini sangat jauh dari harapan. Di TK Pertiwi ini terdapat 13 orang $(76,4 \%)$ anak yang belum mampu berbagi dengan orang lain, belum memiliki rasa percaya diri dan belum mampu bergabung bersama dalam kelompok.

Melihat kenyataan dilapangan di atas, penulis merasa perlu mengadakan penelitian dengan judul "Peningkatan Kecerdasan Interpersonal anak usia 4-5 tahun melalui bermain 
musik". Penulis berharap kecerdasan interpersonal anak dapat meningkat melalui bermain musik sehingga berdampak positif terhadap aspekaspek perkembangan lainnya.

\section{KAJIAN TEORITIK}

\section{Kecerdasan Interpersonal}

Menurut Morgan \& Fonseca (2004: 11) kecerdasan interpersonal adalah kemampuan untuk memahami orang lain, untuk bekerja secara bersama-sama, dan untuk berkomunikasi dengan efektif sebagai bagian dari kecerdasan interpersonal dan dengan kuat menghubungkan pembelajaran bahasa kedua.

\section{Kecerdasan interpersonal}

menurut Tai (2014:3) adalah adalah kemampuan untuk mengerti dan berinteraksi secara aktif dengan oranglain. Kemampuan ini melibatkan komunikasi verbal dan non verbal, kemampuan untuk mencatat perbedaan antara lain, kepekaan terhadap suasana hati dan temperamen orang lain, dan kemampuan untuk menghibur berbagai perspektif. Guru, pekerja sosial, aktor, dan politisi adalah orang-orang yang cerdas secara interpersonal

Menurut Gadner \& Hatch (2011:4) kecerdasan interpersonal adalah Kapasitas untuk membedakan dan menanggapi dengan tepat suasana hati, temperamen, motivasi, dan keinginan orang lain. Dari berbagai pembahasan diatas dapat disintesiskan bahwa kecerdasan interpersonal adalah kapasitas pemahaman yang lebih dalam memahami orang lain, berinteraksi dengan orang lain, dan berkomunikasi secara efektif yang berhubungan erat dengan emosi.

\section{Bermain Musik}

Sejak zaman dahulu anak-anak senang sekali bermain. Aktivitas yang melibatkan fisik ini cenderung membuat anak lupa diri karena pada dasarnya bermain adalah kegiatan yang menyenangkan untuk anak. Melalui bermain anak-anak tidak hanya berkomunikasi dan berinteraksi dengan orang lain tetapi juga membangun pengetahuan bersama dengan orang lain. 
Menurut Battelheim dalam Elizabeth Hurlock (1978:320) kegiatan bermain adalah kegiatan yang tidak mempunyai peraturan lain kecuali yang ditetapkan oleh pemain sendiri dan tidak ada hasil akhir yang dimaksudkan dalam realitas luar. Hal ini artinya bahwa bermain tidak melihat hasil akhir tapi bagaimana proses bermain itu membuat anak senang sehingga anak merasa senang belajar dan dapat mendapatkan pengetahuan. Permainan telah lama menjadi inti program prasekolah. Permainan telah dan akan tetap penting dalam program prasekolah karena anak-anak sangat suka bermain. Permainan anak-anak telah masuk program pembelajaran. Oleh karena itu, program prasekolah harus mendukung pembelajaran lewat permainan. Fitur penerapan program memberi contoh tentang bagaimana permainan dapat mempengaruhi perkembangan sebagai sebuah kebutuhan dan kesatuan yang tak terpisahkan dari kehidupan anak-anak, bayi sampai remaja. Bermain adalah sebuah pekerjaan penting bagi anak, bukan hanya mengeluarkan tenaga saja tetapi melalui bermain anak-anak aktif membangun pengetahuan mereka dengan bereksplorasi terhadap lingkungan.

Gagasan bahwa anak belajar dan berkembang lewat permainan diawali oleh froebel. Sejak masanya, sebagian besar program PAUD telah memasuki permainan dalam kurikulumnya. Montessori melihat keikutsertaan aktif anak dalam materi dan lingkungan yang telah disiapkan sebagai sarana utama mereka memperoleh pengetahuan dan belajar. John Dewey meyakini bahwa anak belajar lewat permainan dan bahwa anak harus mendapat kesempatan untuk ikut dalam permainan yang berhubungan dengan kegiatan seharihari (misal, pusat rumah, kantor pos, toko buah, kantor dokter)

\section{Menurut Koster (2015:283)} Musik adalah suara yang terorganisir. Salah satu tugas mengajar musik adalah mengenalkan anak-anak cara-cara yang berbeda dalam bermain music. Menurut Isbell dan Raines (2007:183) musik adalah bahasa aural yang menggunakan 
unsur-unsur dasar dari nada, ritme, timbre dan bentuk.

\section{Brewer}

(2007:428-429)

menyatakan bahwa musik layaknya seni visual adalah cara dasar pembelajaran, pengalaman dan komunikasi. Semua anak-anak berhak untuk mendapatkan lingkungan musik yang kaya untuk belajar bernyanyi, untuk bermain musik, untuk bergerak dan untuk mendengarkan. Musik juga adalah sebuah alat nilai untuk menolong anak-anak mendapatkan pengetahuan yang masuk akal melalui pengalaman mereka. Lebih lanjut Jackman (2012:281) menyatakan bahwa musik adalah sebuah bahasa, dalam arti untuk berkomunikasi. Komunikasi dilakukan melalui nada, ritme (volume, kisaran, tempo dan gerak. Menurut Stellaccio \& McCarthy (2012:276) musik adalah sarana penting untuk kognitif, sosial dan perkembangan fisik anak.

Dari berbagai pendapat diatas tentang bermain dan musik dapat disintesiskan bahwa bermain musik adalah suatu kegiatan yang menyenangkan untuk anak karena musik memiliki suara yang terorganisir, bahasa aural dan seni visual sebagai alat nilai dan komunikasi untuk menolong anak-anak mendapatkan pengetahuan melalui pengalaman mereka sehingga bermanfaat untuk perkembangan kognitif, sosial dan fisik anak.

\section{METODOLOGI PENELITIAN}

Penelitian ini dilaksanakan pada tanggal 2 januari- 5 februari 2017 dengan sumber data penelitian anak kelompok A berusia 4-5 tahun berjumlah 17 orang. Jenis penelitian ini menggunakan penelitian tindakan (action research). Desain dalam penelitian ini menggunakan Kemmis dan Taggart yang meliputi 4 tahap yaitu tahap perencanaan, tindakan, pengamatan dan refleksi. Dalam model Kemmis dan Taggart tindakan dan observasi dijadikan sebagai suatu kesatuan yang tidak dapat terpisahkan. Teknik pengumpulan data yang digunakan dalam penelitian ini adalah observasi, catatan lapangan dan dokumentasi. 
Lembar instrumen yang telah disiapkan oleh peneliti berisikan indikator-indikator yang merupakan acuan dalam menilai kecerdasan interpersonal anak usia 4-5 tahun. Instrumen ini diisi oleh peneliti dan kolaborator dengan memberikan tanda check list $(\sqrt{ })$ pada setiap indikator yang sesuai dengan tingkatan kecerdasan interpersonal yang muncul pada anak.

Pengolahan data dalam penelitian ini menggunakan dua analisis data yaitu analisis data kuantitatif dan analisis data kualitatif.
Analisis data kuantitatif menggunakan statistik deskriptif dengan cara membandingkan hasil yang diperoleh pada pra siklus sampai siklus II. Analisis data kualitatif dilakukan dengan cara menganalisis data dari hasil catatan lapangan, observasi dan dokumentasi dengan langkah-langkah reduksi data, display data dan verifikasi data.

\section{HASIL DAN PEMBAHASAN}

Data peningkatan kecerdasan interpersonal anak dapat disajikan sebagai berikut:

Tabel 1 Data Peningkatan Tingkat Capaian Perkembangan Kecerdasan Interpersonal Anak Usia 4-5 Tahun di TK Pertiwi Tanjung Raja Tahun 2017

\begin{tabular}{|l|c|c|c|}
\hline Skor & Pra Siklus & Siklus I & Siklus II \\
\hline Rata-rata & & & \\
\hline Peningkatan & 33,8 & 50,4 & 60,7 \\
\hline
\end{tabular}

Dari tabel di atas dapat kita lihat bagaimana peningkatan kecerdasan interpersonal anak meningkat dari pra siklus, siklus I dan siklus II. Pada siklus II rata-rata tingkat capaian perkembangan (TCP) anak telah mencapai kriteria keberhasilan yang ditentukan oleh peneliti dan kolaborator, sehingga penelitian tindakan ini dikatakan telah berhasil. Melihat hasil penelitian diatas, Berbicara tentang bermain musik dan kaitannya dengan kecerdasan interpersonal sesuai dengan variabel yang diteliti oleh peneliti. Hal ini sesuai dengan apa yang dikatakan oleh 
Stellaccio \& McCarthy dalam Hallam (2012:276) yang menyatakan bahwa kecerdasan interpersonal anak dapat meningkat melalui bermain musik karena musik adalah sarana penting untuk perkembangan kognitif, sosial dan perkembangan fisik anak. Musik tidak hanya sebuah suara yang hanya bisa didengar tetapi merangsang seseorang untuk mampu bersosialisasi dan berkomunikasi dengan orang lain.

Dalam hal ini secara sosial atau kecerdasan interpersonal anak-anak sudah mampu untuk berbagi dengan orang lain seperti berbagi bekal dan mainan, anak mampu menolong orang lain seperti meminjamkan pensil, penghapus dan crayon kepada temantemannya yang tidak membawa, anak mampu menghargai (memuji) karya orang lain seperti anak-anak bertepuk tangan kepada temannya yang berani maju dan mengacungkan jempol, anak mampu bekerja sama dengan orang lain dan memiliki rasa percaya diri seperti anak-anak mau bermain musik bersama, mau bernyanyi bersama, mau bermain bertepuk tangan bersama dalam kelompok.

Selain itu melalui bermain musik Anak-anak belajar tentang budaya mereka seperti mereka bernyanyi lagu-lagu tradisional, dan mereka mengembangkan kemampuan kerja sama seperti mereka bekerja sama dalam menciptakan gerak musik. Hal ini tentunya dapat meningkatkan kecerdasan interpersonal anak dalam hal kerja sama dengan orang lain. Untuk menciptakan gerak musik dan bermain musik yang indah dibutuhkan kerja sama antara kelompok. Di dalam penelitian ini misalnya, sangat dibutuhkan sekali kekompakan anak untuk bermain musik dengan bahanbahan sederhana agar tercipta suarasuara yang indah sesuai dengan nada. Selain itu ketika bertepuk tangan, anakanak juga harus kompak agar suara tepuk tangan yang dihasilkan tidak kacau dan nikmat untuk di dengar.

Selain hal-hal yang di sebutkan di atas kecerdasan interpersonal anak juga dapat meningkat melalui bermain musik seperti anak mampu 
mengungkapkan perasaan sedih dan senang, anak-anak dapat terlihat begitu empati kepada orang lain karena mereka mampu merasakan apa yang orang lain rasakan, anak mampu menceritakan pengalaman-pengalaman yang ia dapat kepada teman-temannya dan mampu mengucapkan terimakasih ketika di berikan dan dipinjamkan sesuatu

Dalam hal ini kegiatan bermain musik yang dilakukan oleh peneliti adalah secara berkelompok sebagaimana yang dikemukakan oleh Amstrong bahwa salah satu strategi pengajaran untuk meningkatkan kecerdasan interpersonal adalah dengan berkelompok sehingga anak dapat membangun dan berinteraksi dengan orang lain. Proses pembelajaran berkelompok membutuhkan sikap keberanian anak untuk mampu bekerja sama, berinteraksi dan membangun komunikasi bersama teman-temannya.

Pembelajaran berkelompok mengajarkan anak sebuah kekompakan untuk bersama-sama menciptakan sesuatu yang indah dalam hal ini tentunya bagaimana anak-anak kompak untuk bermain musik bersama, selain itu pembelajaran kelompok juga memberikan anak pengalaman bahwa ia adalah makhluk sosial yang sangat membutuhkan orang lain untuk bekerjasama, untuk saling tolongmenolong, untuk saling berbagi dan saling menghargai.

Selanjutnya Hallam (2010: 1-7) dengan judul penelitian The power of music: its impact on the intellectual, social and personal development of children and young people. Hasil penelitian ini menjelaskan bahwa musik berpengaruh terhadap kecerdasan, sosial dan perkembangan pribadi pada anak-anak dan orangorang muda. Musik sangat besar kekuatan dan dampaknya bagi anak.

Penelitian Hallam di atas senada dengan Morrison (2012:222) yang berpendapat bahwa seorang anak yang memiliki kecerdasan interpersonal akan suka bergaul dengan orang lain, melaksanakan pembelajaran secara bersama-sama dalam kelompok dan cenderung peduli serta peka terhadap lingkungan sekitar. Seorang yang 
cerdas secara interpersonal dapat dengan mudah memahami situasisituasi yang ada di lingkungan sekitar mereka dan mencoba untuk terlibat aktif dalam lingkungan tersebut. Hal ini terjadi karena seseorang yang cerdas secara interpersonal memiliki empati yang tinggi, yang ingin turut merasakan apa yang orang lain rasakan. 
Dalam bidang psikologi menurut Gadner \& Hatch (2011:4) kecerdasan interpersonal adalah Capacities to discern and respond appropriately to the moods, temperaments, motivations, and desires of other people. Pernyataan ini dapat diinterpretasikan bahwa kecerdasan interpersonal adalah Kapasitas untuk membedakan dan menanggapi dengan tepat suasana hati, temperamen, motivasi, dan keinginan orang lain. Untuk dapat memahami suasana hati, temperamen motivasi dan keinginan orang lain maka butuh pemahaman mendalam tentang jiwa orang tersebut. Hal ini erat kaitannya dengan ilmu psikologi bahwa seorang anak yang cerdas secara interpersonal pastinya dapat memahami pikiran dan perasaan orang lain sehingga anak memahami tindakan apa yang akan dilakukan kepada orang tersebut. Seseorang yang cerdas secara interpersonal juga memiliki sikap empati dan sikap ini muncul karena seseorang berusaha untuk ingin merasakan apa yang orang lain rasakan. Secara psikologis, orang yang memiliki sikap empati yang tinggi cenderung akan merasa sedih dan bersalah jika tidak menolong orang lain yang ia lihat dalam keadaan susah. Sebisa mungkin ia akan menolong orang tersebut agar lepas dari penderitaannya baik dari segi moral atau materi.

Individu yang memiliki kecerdasan interpersonal akan memiliki kemampuan untuk memahami perasaan orang lain, bermotivasi tinggi, dan dapat berinteraksi dengan baik dengan orang lain melalui komunikasi yang efektif. Hal ini menunjukkan bahwa kecerdasan interpersonal seseorang sangat tergantung pada bagaimana ia dapat mengolah emosinya sendiri. Emosi yang ditimbulkan oleh seseorang diatur di dalam otak untuk mampu merasakan sedih, marah, kecewa dan bahagia. Jadi kecerdasan interpersonal ini juga erat kaitannya dengan ilmu neurosains yang juga terkait dengan kognitif.

Vygotsky dalam Jackman (2012: 283) menyatakan bahwa perubahan pada proses struktur otak sangat penting terjadi tidak hanya pada otak itu sendiri tetapi bagaimana otak berpengaruh terhadap anak-anak yang berinteraksi dengan lingkungan 
dan bagaimana lingkungan tersebut berinteraksi pada anak. Oleh karena itu penting dilakukan stimulasi kecerdasan interpersonal sejak dini salah satunya adalah melalui kegiatan bermain musik.

Ditinjau dari segi bahasa Morgan dan Fonseca (2004:1-6) menyatakan bahwa seseorang yang cerdas secara interpersonal tidak hanya mampu untuk memahami orang lain tapi juga mampu untuk berkomunikasi dengan orang-orang tersebut. Hal ini seperti yang telah diungkapkan bahwa "The ability to understand other people, to work cooperatively and to communicate effectively is part of the interpersonal intelligence and strongly connected to learning a second language. Pendapat ini dapat diinterpretasikan bahwa kecerdasan interpersonal adalah kemampuan untuk memahami orang lain, untuk bekerja secara bersamasama, dan untuk berkomunikasi dengan efektif sebagai bagian dari kecerdasan interpersonal dan dengan kuat menghubungkan pembelajaran bahasa kedua.

Anak yang aktif berinteraksi dengan orang lain pasti juga akan membangun komunikasi dengan orang-orang tersebut. Bahasa adalah alat komunikasi anak untuk berinteraksi dan bekerja sama dengan orang lain. Melalui bahasa anak-anak dapat mengungkapkan perasaan mereka dan apa yang ada dalam pikiran mereka. Selain itu, bahasa juga membuat anak memiliki rasa percaya diri serta keberanian untuk membangun komunikasi dengan orang lain.

Menurut Jackman(2012:81) proses pembelajaran bahasa sangat penting dilakukan. Anak-anak belajar bahasa melalui mendengar dan berbicara.

Dari segi sosial menjelaskan bahwa anak adalah makhluk sosial yang selalu membutuhkan orang lain. Dapat diartikan bahwa kecerdasan interpersonal melibatkan interaksi seseorang dengan orang lain. Dimana dalam hubungan sosial tersebut terdapat kontak fisik yang berupa sentuhan-sentuhan untuk memberikan dukungan dan motivasi kepada orang lain yang juga dikomunikasikan dalam bentuk Bahasa. 
Menurut Morrison (2012:222)

adalah sebuah tanggung jawab guru untuk meningkatkan dan mendorong perkembangan sosial anak. Perkembangan sosial dan emosi yang positif memudahkan anak belajar dengan lebih baik dan berhasil dalam semua aktivitas di sekolah dan dalam hidup. Selanjutnya Morrison menyatakan bahwa kegiatan yang dapat merangsang kecerdasan interpersonal anak adalah memberikan anak kebebasan untuk mencari tahu, memberikan proyek dan aktivitas yang memudahkan anak untuk menemukan dan bereksperimen, mendukung usaha anak untuk merancang, membuat sesuatu dan terlibat dalam kegiatan tersebut.

Selain itu menurut Bandura dalam Brewer (2007:230) hal yang paling penting dalam pembelajaran sosial pada anak adalah guru harus dapat menjadi contoh model perilaku yang baik sehingga dapat ditiru oleh anak. Pengalaman-pengalaman yang didapatkan oleh anak adalah pondasi penting untuk pembelajaran sosial mereka. Semakin baik contoh yang dilihat anak maka semakin baik pula pembelajaran sosial mereka. Sedangkan jika anak berada di rumah maka orangtua adalah contoh teladan yang paling baik dalam pembelajaran sosial anak. Orangtua harus memberikan anak-anak mereka kesempatan dan pengalamanpengalaman nyata untuk berinteraksi, membangun komunikasi dan kepercayaan diri anak melalui aktivitas bermain yang disukai oleh anak.

\section{KESIMPULAN DAN SARAN}

Proses pembelajaran bermain musik yang dilaksanakan selama II siklus ini meliputi tahap kegiatan awal, inti dan akhir. Kegiatan awal dilakukan untuk memberikan anak motivasi dan apersepsi tentang pembelajaran yang akan dilakukan anak agar anak semangat dan antusias mengikuti proses pembelajaran. Kegiatan inti dilakukan dengan kegiatan bermain musik sesuai dengan tujuan yang telah ditetapkan dalam rencana pelaksanaan pembelajaran, memberikan reward dan pujian kepada anak yang telah berhasil. Selain itu pada kegiatan ini guru dan peneliti juga mengamati 
perkembangan kecerdasan interpersonal anak.

Terjadi peningkatan kecerdasan interpersonal anak melalui kegiatan bermain musik. Proses pembelajaran bermain musik yang menyenangkan membuat anak mau bekerja sama dengan orang lain, memiliki rasa percaya diri, anak mau berbagi dengan orang lain dan akhirnya anak juga senang bermain dengan orang lain. Peningkatan dari pra siklus ke siklus I adalah 16,6 dengan hasil pada siklus I sebesar 50,4. Peningkatan dari siklus I ke siklus II adalah 10,3 dengan hasil pada siklus II sebesar 60,7 dan berada pada kategori berkembang sangat baik (BSB). Berdasarkan kesimpulan yang telah dijelaskan. Adapun saran yang bisa diberikan peneliti adalah sebagai berikut a) Bagi guru diharapkan dapat memberikan anak lebih banyak kesempatan untuk mengembangkan diri anak melalui bermain musik b) Guru juga harus kreatif mencari kegiatan lain yang dapat merangsang kecerdasan interpersonal anak. c) Guru dan Orangtua harus lebih banyak menstimulasi kecerdasan interpersonal anak sebagai bagian dari life skill untuk modal kesuksesan hidup. d) Anak-anak harus lebih sering diperdengarkan musik karena musik adalah kekuatan jiwa.

\section{DAFTAR PUSTAKA}

Elizabet B. Hurlock. 1978. Perkembangan Anak. Jakarta. PT. Gelora Aksara Pratama.

Eva Brand dan Ora Bargil. 2010. Improving Interpersonal Communication through Music

Fang-Mei Tai. 2014. Exploring Multiple Intelligences . The Journal of Human Resource and Adult Learning, Vol. 10, N 12 um. 1, June 2014 issue.

S. Filivopic dan G. GrujicGaric.2011. The Influence of Music on the Children"s Art Expression. Journal plus education, ISSN:1842-077X, EISSN(online) 2068-1151 Vol VII (2011), NO 2, pp 223-240

George Morisson. 2012. DasarDasar Pendidikan Anak Usia Dini. Jakarta: Indeks.

\section{Hilda L. Jackman. Early Education Curriculum A child's Connection to The World. USA: Wadsworth.2012.}

Howard Gardner and Thomas Hatch.1989. Multiple Intelligences Go to School: Educational Implications of the 
Theory of Multiple Intelligences. Journal of Educational Researcher, Vol. 18, No. 8 (Nov., 1989), pp. 4-10 Published by: American Educational Research Association.

Jane Arnold Morgan \& $\mathrm{M}^{\mathrm{a}}$ Carmen Fonseca. 2004. Multiple Intelligence Theory and Foreign Language Learning: A Brain-based Perspective. IJES, vol. 4 (1), 2004, pp. 119-136

Jo Ann Brewer. Early Childhood Education Preschool Through Primary Grades. 2007. USA: America.

Joan Bouza Koster. Growing Artists Teaching The Arts to Young Children. USA: Wadswort.

Jonathan Bolduc: 2009. Effects Of a Music Programme On Kindergartners Phonological Awareness Skills. International Journal of Music Education Vol

27(1).3747(200902)27.1.10.11 77/0255761408099063

Katrin Hille, et all : 2011. Association Between Music Education, Intelligence, And Spelling Ability In Elementary School. Research Article Advances In Cognive Psyschology Volume 7: 16 DOI:10.2478/v10053-008-0082-4

Kelly R.Paquette dan Sue A. Rieg. The Influence of Music on the Children"s Art Expression.
Early Childhood Educ J (2008)

36:227-232.

DOI

10.1007/s 10643-008-0277-9

Rebecca T. Isbell \& Shirley C. Raines. Creativity And The Arts With Young Children. Canada: Delmar.2007

S. Filivopic dan G. GrujicGaric.2011. The Influence of Music on the Children"s Art Expression. Journal plus education, ISSN:1842-077X, EISSN(online) 2068-1151 Vol VII (2011), NO 2, pp 223-240

Susan Hallam:2010. The Power Of Music : Its Impact On The Intellectual, Social And Personal Development Of Children And Young People. International Journal Of Music Education 28:269. DOI:10.1177/02557614103706 58

Thomas Amstrong. Multiple Intelligences In The Clasroom. USA:AS 
PERNIK Jurnal PAUD, VOL 1 NO.1 September 2018 